\title{
Dinâmica do Banco de Sementes de ArRoz-Vermelho Afetado pelo Pisoteio bovino e Tempo de Pousio da Área ${ }^{1}$
}

\author{
Red Rice Seed Bank Dynamics Affected by Cattle Trampling and Fallow Duration
}

MARCHEZAN, E. ${ }^{2}$, OLIVEIRA, A.P.B.B. ${ }^{3}$, AVILA, L.A. ${ }^{4}$ e BUNDT, A.L.P. ${ }^{5}$

\begin{abstract}
RESUMO - Para avaliar a influência do pisoteio bovino e do tempo de pousio na dinâmica do banco de sementes de arroz-vermelho foi conduzido um experimento em lavoura comercial de arroz irrigado, que adota o sistema de cultivo mínimo, seguido de dois anos de pousio, manejada, nesse período, pelo pastejo de bovinos. O delineamento experimental foi o de blocos ao acaso, com três repetições no esquema bifatorial. O fator A constou dos manejos pós-colheita da cultura de arroz: [M1] - pousio com pisoteio animal e [M2] - pousio sem pisoteio animal. O fator B constou dos anos de amostragem: [A1] - 1999, [A2] - 2000 e [A3] - 2001. O banco de sementes de arroz-vermelho foi estimado através de 12 amostras de solo por parcela, em abril de 1999, abril de 2000 e abril de 2001, com trado cilíndrico de $10 \mathrm{~cm}$ de diâmetro. As profundidades de coleta das amostras de solo foram de 0-1 cm, 1-5 cm, 5-10 cm e 10-15 cm. Após a coleta, os grãos de arroz-vermelho foram separados do solo, contados e submetidos ao teste de tetrazólio, para estimativa da viabilidade. O pisoteio bovino não afetou a distribuição das sementes no perfil do solo, bem como a dinâmica do banco de sementes. Houve efeito do tempo de pousio sobre o banco de sementes de arroz-vermelho; a equação que melhor explica a correlação entre número de sementes viáveis e tempo de pousio, em meses, foi a equação exponencial $\mathrm{y}=1382,15 \exp \left(-0,1988^{*} \mathrm{x}\right) \mathrm{p}<0,05$, demonstrando $\mathrm{o}$ decréscimo de 1.448 para 151 (90\% de redução) em 12 meses e para 38 (98\% de redução) sementes viáveis por $\mathrm{m}^{2}$ em 24 meses de pousio. Com relação às profundidades de enterrio das sementes de arroz-vermelho, foi observado que, para o ano de 2000, a redução do banco de sementes foi maior na superfície do solo, enquanto para o ano de 2001 não houve diferença significativa entre as profundidades. As sementes que estavam na superfície do solo perderam a viabilidade rapidamente, em torno de $99 \%$ em um ano de pousio, tanto na presença como na ausência de pisoteio. Conclui-se que o pisoteio animal não interfere na dinâmica do banco de sementes de arroz-vermelho da área em pousio. O pousio do solo, com ou sem pisoteio animal, reduz o banco de sementes de arroz-vermelho.
\end{abstract}

Palavras-chave: integração lavoura/pecuária, manejo de plantas daninhas, Oryza sativa.

ABSTRACT - An experiment was conducted in a commercial lowland rice-producing area, adopting the minimum tillage system of rice production, followed by two years of fallow, managed, during this time, by cattle production, in order to evaluate the influence on red rice seed bank dynamics. The experimental design was randomized complete blocks, with three replications, in a bifactorial design. Factor A consisted of rice post-harvest management of the area: [T1] - fallow with cattle trampling and [T2] - fallow without cattle trampling. Factor B was the sampling time: [A1] 1999, [A2] 2000 and [A3] - 2001. The red rice seed bank estimation was made using 12 soil samples by plot, in April 1999, April 2000 and April 2001, using a $10 \mathrm{~cm}$ diameter cylinder soil sampler. The sampling depths were 0-1 cm, $1-5 \mathrm{~cm}, 5-10 \mathrm{~cm}$ and $10-15 \mathrm{~cm}$. After being extracted from the soil, the grains of red rice were counted and submitted to a tetrazolium test to estimate seed viability. Cattle trampling did not affect seed distribution in the soil profile and the dynamics of the red rice seed bank. Fallow duration affected the seed bank of red rice; the regression

Recebido para publicação em 22.2.2002 e na forma revisada em 2.4.2003.

Eng.-Agr., Dr., Prof. Titular, Pesquisador CNPq, Departamento de Fitotecnia da Universidade Federal de Santa Maria - UFSM, Centro de Ciências Rurais, 97105-900 Santa Maria-RS, Fone: (055) 220-8451, <emarch@ccr.ufsm.br>; ${ }^{3}$ Acadêmica do curso de Agronomia da UFSM, bolsista FAPERGS; ${ }^{4}$ Eng.-Agr., M.S., Professor Assistente do Departamento de Fitotecnia da UFSM; ${ }^{5}$ Eng.-Agr. formado pela UFSM em agosto de 2001. 
equation fit that best explains the correlation between number of viable seeds and fallow duration in months was the exponential equation: $y=1382.15 \exp \left(-0.1988^{*} x\right) p<0.05$, showing a decrease in the number of seeds within 12 months, from 1,448 to 151 (90\% reduction), and 38 (98\% reduction) viable seeds per square meter in 24 months of fallow. Regarding the red rice seed burial depths, seed bank reduction was greater on the soil surface in 2000, with no difference between the depths in 2001. The seeds located on the soil surface lost their viability rapidly, with an average of $99 \%$ within one year fallow with or without cattle trampling. It can be concluded that cattle trampling does not affect red rice seed bank dynamics in fallow areas. Soil fallow, with or without cattle trampling, reduces in the red rice seed bank.

Key words: integration crop/cattle production, weed management, Oryza sativa.

\section{INTRODUÇÃO}

A cadeia produtiva do arroz irrigado desempenha um papel importante na economia brasileira; no Rio Grande do Sul, responsável por cerca de $50 \%$ da produção nacional, ela envolve uma área aproximada de 950 mil ha cultivados e cerca de 10 mil produtores (EMBRAPA, 2001). Aliada à atividade orizícola encontra-se a produção animal, especialmente de bovinos, os quais são mantidos na resteva do arroz irrigado do período pós-colheita até o preparo do solo para a safra seguinte, ou durante o pousio da área, de um ou dois anos, em média. Uma das principais razões para deixar a área em pousio de cultivo de arroz é não elevar o banco de sementes de arroz-vermelho.

Várias técnicas de manejo vêm sendo avaliadas com o objetivo de combater esta planta daninha, porém poucas se destacam no seu controle eficaz, sendo recomendado o uso integrado de métodos de controle para evitar a proliferação da invasora (Marchezan, 1994), pois, dentre as características do arroz-vermelho, a mais relevante encontra-se na longevidade das sementes no solo, devido à dormência e viabilidade destas por vários anos, dependendo das condições ambientais e dos ecótipos de arroz-vermelho presentes na área (Goss \& Brown, 1939; Noldin, 1995).

A importância da dormência como mecanismo de sobrevivência está na garantia da distribuição da germinação, manutenção do banco de sementes e propagação de espécies por longos períodos, mesmo sob condições desfavoráveis e mobilizações contínuas do solo. As sementes quiescentes armazenadas no solo podem apresentar perda de viabilidade, predação, germinação ou indução de dormência secundária (Carmona, 1992).
Vários fatores afetam a dormência das sementes de espécies vegetais presentes no banco de sementes do solo. Benech-Arnold et al. (2000) citam a flutuação de temperatura, presença ou ausência de luz, concentração de nitrato, gases como $\mathrm{O}_{2}$ e $\mathrm{CO}_{2}$ e práticas agrícolas.

A dinâmica do banco de sementes de muitas espécies pode ser afetada pelo manejo do solo, pelos sistemas de cultivo utilizados e pelas culturas implantadas; o estabelecimento das plantas daninhas sofre influência direta da superação da dormência do banco de sementes (Ghersa et al., 1997), além de o manejo do solo ser variável indireta sobre a emergência das plântulas (Forcella et al., 2000).

Observando dados de Noldin (1995) sobre a longevidade de sementes de arroz-vermelho no solo, verifica-se que as sementes depositadas na superfície deste perdem viabilidade rapidamente, indicando que após a colheita do arroz, em áreas infestadas com a invasora, os produtores devem evitar a adoção de práticas de manejo do solo que provoquem o enterrio das sementes, pois estas aumentam a sua longevidade quando localizadas a maiores profundidades no solo. Nesse sentido, Helpert (1981) constatou que $12 \%$ das sementes de arroz-vermelho emergiram a $12 \mathrm{~cm}$ de profundidade, enquanto a $16 \mathrm{~cm}$ a emergência foi de apenas $1 \%$ das sementes. Gealy et al. (2000) observaram que todos os ecótipos testados emergiram de profundidades de até $7,5 \mathrm{~cm}$, independentemente da textura do solo.

Dessa forma, a manutenção das sementes de arroz-vermelho na superfície do solo é uma prática de manejo para redução do banco de sementes, porém não se conhece o efeito do pisoteio animal sobre o posicionamento das 
sementes no solo e, conseqüentemente, sobre a dinâmica do banco de sementes de arroz-vermelho.

Assim, este trabalho foi conduzido com o objetivo de avaliar a influência do pisoteio de bovinos e do tempo de pousio do solo na dinâmica do banco de sementes de arroz-vermelho em área de várzea de arroz irrigado.

\section{MATERIAL E MÉTODOS}

O experimento foi conduzido no município de Santa Maria, Rio Grande do Sul, em área de várzea e em solo classificado como Planossolo Hidromórfico Eutrófico arênico, com infestação média de 1.448 grãos de arroz-vermelho por $\mathrm{m}^{2}$, cujas principais características físicas e químicas são: argila $=18 \%, \mathrm{pH}=4,8$, índice $\mathrm{SMP}=5,6, \mathrm{P}=4,0, \mathrm{~K}=30, \% \mathrm{MO}=1,5, \mathrm{Al}$ $\mathrm{cmol}_{c} \mathrm{~L}^{-1}=1,0, \mathrm{Ca}=1,5, \mathrm{Mg}=0,3$. O ensaio foi instalado em área de lavoura comercial que adota o sistema de cultivo mínimo de arroz irrigado, seguido de dois anos de pousio com utilização de bovinos na área. O delineamento experimental utilizado foi o de blocos ao acaso com três repetições, sendo o mesmo para os três anos de condução do ensaio, com os manejos [M1] - pousio com pisoteio animal e [M2] - pousio sem pisoteio animal e os anos de amostragem [A1] - 1999, [A2] - 2000 e [A3] 2001. Quanto à coleta, esta foi realizada nas profundidades de 0-1 cm [P1], $1-5 \mathrm{~cm}$ [P2], 5-10 cm [P3] e 10-15 cm [P4]. As unidades experimentais mediram $4 \times 4 \mathrm{~m}$ e para o manejo [M2] as parcelas foram cercadas para impedir o acesso dos animais.

Em abril de 1999, iniciaram-se as coletas de solo, objetivando estimar o número inicial de sementes de arroz-vermelho existentes na área, o qual gerou dados utilizados para posterior análise da dinâmica do banco de sementes no decorrer dos anos, sob a influência dos dois manejos. A coleta de solo para a estimativa do banco de sementes de arroz-vermelho foi realizada através de 12 amostras de solo por parcela, em abril de 1999, abril de 2000 e abril de 2001, com trado cilíndrico de $10 \mathrm{~cm} \mathrm{de}$ diâmetro.

Após a coleta, os grãos de arroz-vermelho foram retirados do solo através de lavagem das amostras em água corrente, peneiradas em peneira de $2 \mathrm{~mm}$. Após secos, os grãos foram submetidos ao teste de tetrazólio, seguindo a metodologia descrita por Rocha (1976). Com base nesta metodologia, avaliou-se o número de sementes viáveis de arroz-vermelho por $\mathrm{m}^{2}$ em quatro profundidades e o banco de sementes total (soma de todas as profundidades), além das análises entre os anos. Além disso, em cada parcela foi feito o monitoramento do percentual de redução do banco de sementes, através da fórmula:

Redução do banco

de sementes $(\%) \quad=100-(($ Nsano*100 $) /$ Nsant $)$

em que Nsano = número de sementes de arrozvermelho encontrado no ano; e Nsant = número de sementes de arroz-vermelho encontrado no ano anterior.

No primeiro ano, foi calculada a redução ocorrida de 1999 para 2000. No segundo ano, o cálculo descrito acima foi feito de duas formas, tomando-se como base o banco de sementes do ano anterior (2000) e o primeiro ano (1999), para verificar o efeito de dois anos de pousio.

Para análise, o experimento foi considerado bifatorial em blocos ao acaso com parcelas subdivididas, com o fator pousio (com ou sem pisoteio bovino) e o fator ano $(1999,2000$ e 2001); para análise estatística, os dados de número de sementes foram transformados para raiz quadrada e os de percentagem de viabilidade, para arco seno. Os dados foram submetidos à análise de variância e suas médias comparadas pelo teste de Tukey.

\section{RESULTADOS E DISCUSSÃO}

No início do experimento (1999), a área encontrava-se altamente infestada por arrozvermelho, com média de 1.448 sementes viáveis por metro quadrado.

Com relação ao banco de sementes total soma das sementes encontradas em todas as profundidades do solo $(0-15 \mathrm{~cm})-$, constatouse que não houve efeito do pisoteio animal, havendo apenas efeito do tempo de permanência das sementes no solo. Por meio da análise de regressão do número de sementes por metro

Planta Daninha, Viçosa-MG, v.21, n.1, p.55-62, 2003 
quadrado e do tempo de pousio da área em meses, notou-se que a equação que melhor explicou a correlação entre as duas variáveis foi a exponencial $\mathrm{y}=1382,15 \exp \left(-0,1988^{*} \mathrm{x}\right)$ $\mathrm{p}<0,000$ (Figura 1). A redução do número de sementes por metro quadrado foi bastante drástica no primeiro ano, partindo-se de 1.448 para menos de 151 sementes por metro quadrado 12 meses depois e menos de 38 aos 24 meses. Esses dados foram semelhantes àqueles encontrados por Avila et al. (2000), que observaram redução de 538 sementes por metro quadrado para 110 (6 meses), chegando a 0 semente de arroz-vermelho ( 18 meses), com amostragem até $10 \mathrm{~cm}$ de profundidade.

Os valores em percentagem de redução são apresentados na Tabela 1 , notando-se que a redução foi de $90 \%$ com apenas 12 meses de pousio e de $80 \%$ no segundo ano; embora com redução numericamente menor no segundo ano, não houve diferença entre os dois valores, com média de $85 \%$ de redução por ano.

A redução do banco de sementes em dois anos de cultivo foi de $98 \%$ (Tabela 1), demonstrando a eficiência desta prática de manejo, tão difundida entre os orizicultores, na redução da infestação de arroz-vermelho nas áreas destinadas ao cultivo do arroz irrigado. Esses resultados foram semelhantes àqueles encontrados por Avila et al. (2000), que, avaliando a evolução do banco de sementes e controle do arroz-vermelho em diferentes sistemas de manejo do solo de várzea, constataram que o pousio do solo por um ano proporcionou $80 \%$ de redução do banco de sementes e por dois anos promoveu a redução próxima a $100 \%$ do banco de sementes de arroz-vermelho.

Tabela 1 - Redução, em percentagem, do banco de sementes total (soma de todas as profundidades). Santa MariaRS. 2001

\begin{tabular}{|l|c|c|c|}
\hline \multirow{2}{*}{ Condição } & \multicolumn{2}{|c|}{ Efeito de um ano de pousio } & $\begin{array}{c}\text { Efeito de dois } \\
\text { anos de pousio }\end{array}$ \\
\cline { 2 - 4 } & $\begin{array}{c}2000 \\
\text { comparado } \\
\text { com } 1999\end{array}$ & $\begin{array}{c}2001 \\
\text { comparado } \\
\text { com } 2000\end{array}$ & $\begin{array}{c}2001 \\
\text { comparado } \\
\text { com o início de } \\
1999\end{array}$ \\
\hline Com pisoteio & $90^{\mathrm{ns}}$ & $82^{\mathrm{ns}}$ & $98^{\mathrm{ns}}$ \\
Sem pisoteio & 90 & 77 & 98 \\
\hline Média & $90^{\mathrm{ns}^{+}}$ & 80 & 98 \\
CV\% & 5,0 & 35,7 & 7,5 \\
\hline
\end{tabular}

Para análise, dados transformados para RAIZ $(\mathrm{X}+0,5)$

${ }^{n s}$ Teste $\mathrm{f}$ não-significativo a $5 \%$ de probabilidade.

${ }^{\text {ns }}{ }^{+}$Este teste somente comparou o efeito de um ano de pousio (2000/99 e 2001/2000).

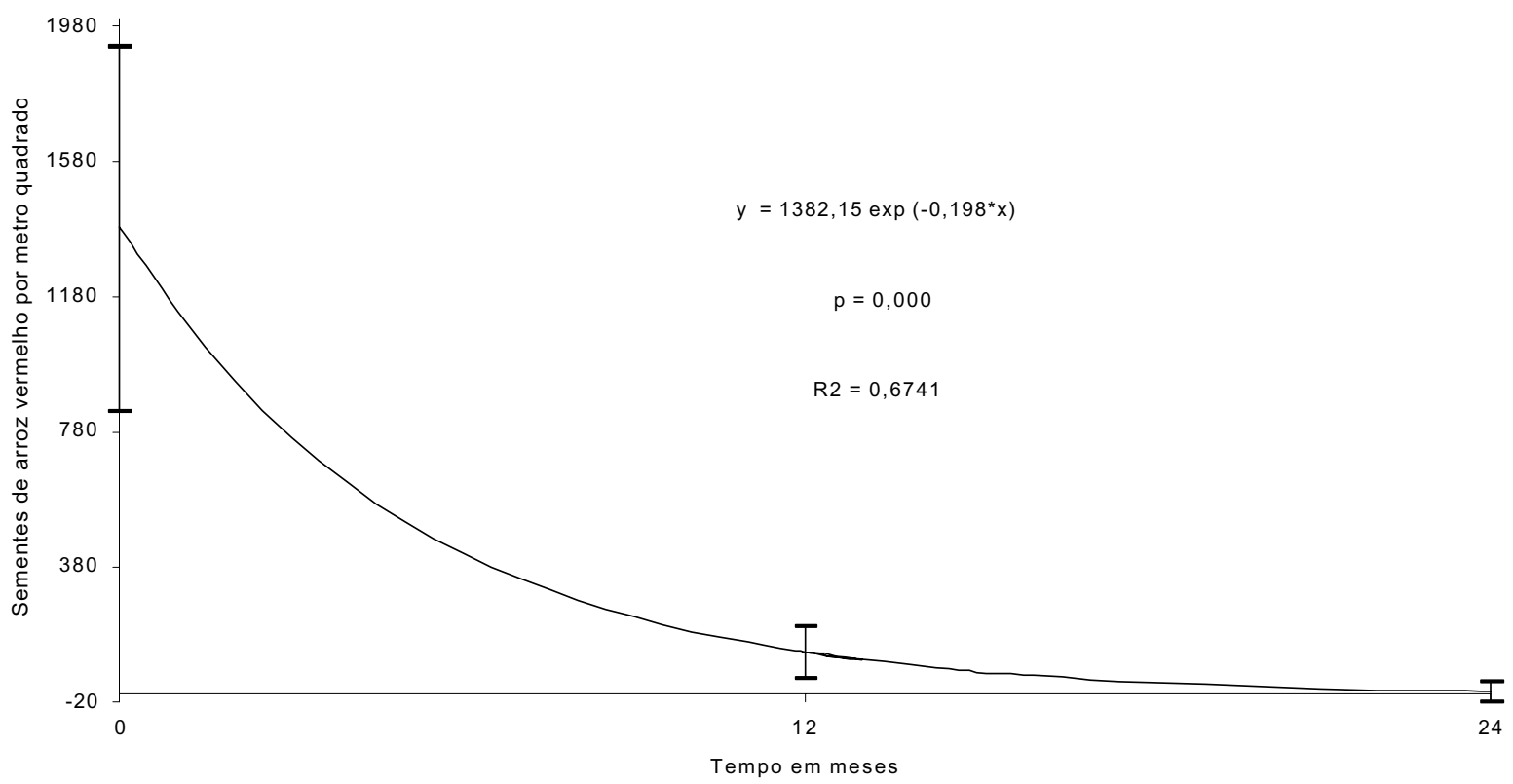

Figura 1 - Efeito do tempo de pousio sobre o número de sementes de arroz vermelho por metro quadrado, na soma de todas as profundidades de coleta. Santa Maria-RS. 2001. 
A redução do banco de sementes de arrozvermelho com o pousio do solo, entre outros fatores, se deve à germinação das sementes e ao consumo das plantas por animais, como bovinos. Segundo Vidotto \& Ferrero (2000), as sementes de arroz-vermelho em campo atingem o máximo potencial germinativo aos 153 dias após a colheita dos grãos.

Apesar de terem restado 35 sementes viáveis de arroz-vermelho por metro quadrado após o segundo ano de pousio (Figura 1), observa-se na Figura 2 que, na profundidade de 0-5 cm, em que as sementes são mais aptas a gerar plantas, encontram-se apenas 18,5 sementes por metro quadrado; de acordo com Vidotto \& Ferrero (2000), as sementes de arrozvermelho em solo inundado emergem de uma profundidade máxima de $5 \mathrm{~cm}$, ao passo que com solo em capacidade de campo pode haver até $18 \%$ de emergência das sementes localizadas na profundidade de $5-10 \mathrm{~cm}$.

Com relação ao número de sementes de arroz-vermelho em cada profundidade (Figura 2 ), nota-se que, no primeiro ano, o maior número de sementes encontrava-se na superfície do solo, com média de 1.139 sementes por metro quadrado, demonstrando que grande parte das sementes que havia no solo após a colheita do arroz era proveniente do degrane do arroz-vermelho produzido naquele ano, corroborando os dados encontrados por Avila et al. (2000), que observaram degrane de 1.266 sementes viáveis de arroz-vermelho por metro quadrado no sistema de semeadura direta; as sementes provindas do degrane correspondiam a $77 \%$ do banco de sementes do solo.

No segundo ano, o número de sementes que estavam na superfície do solo reduziu para 16 por metro quadrado e, no terceiro, para apenas 1,5 semente; muitas dessas sementes perderam a viabilidade ou ficaram sujeitas à predação por animais. Trabalhos de Noldin (1995) demonstraram que as sementes presentes na superfície do solo sofrem rápida perda de viabilidade quando comparadas com aquelas depositadas em maiores profundidades.

Na Figura 3 encontram-se os percentuais de redução do banco de sementes de arroz-vermelho, para melhor verificar o impacto do tempo e da profundidade na dinâmica do banco de sementes. Nota-se que, ao refazer os cálculos com as médias das sementes viáveis $\mathrm{m}^{2}$ (Figura 2 ), não

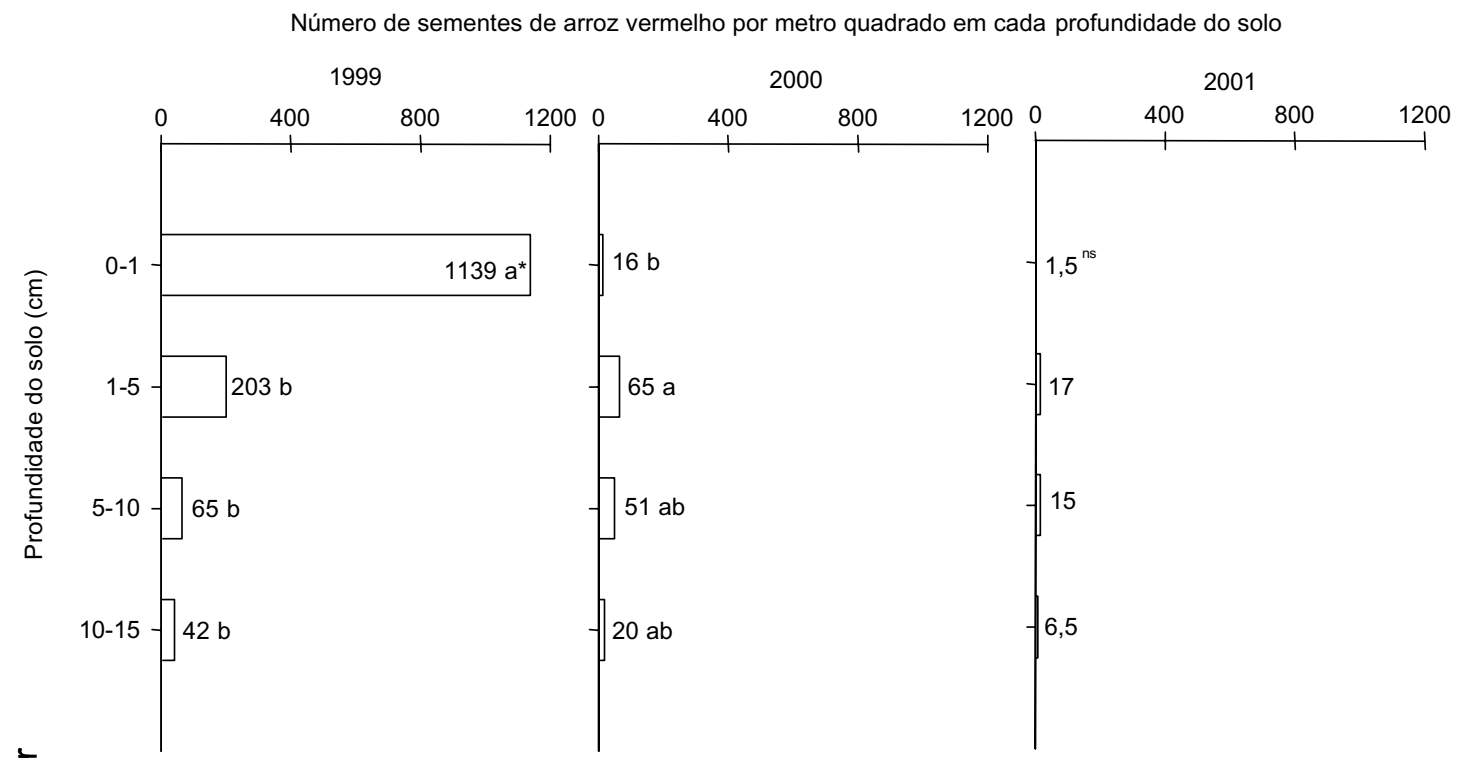

Para análise, dados transformados para raiz quadrada.

ns Teste $\mathrm{F}$ não-significativo a $5 \%$ de probabilidade.

* Médias não ligadas por mesma letra diferem pelo teste de

$\circ$

Tukey a $5 \%$ de probabilidade.

Figura 2 - Número de sementes viáveis de arroz vermelho por metro quadrado no banco de sementes do solo, em cada profundidade. Santa Maria-RS. 2001.

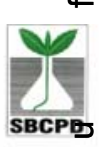

Planta Daninha, Viçosa-MG, v.21, n.1, p.55-62, 2003 
se obtêm os mesmos valores, porque os valores foram calculados para cada parcela e o que é apresentado é a média das percentagens e não a percentagem das médias.

O percentual de redução do banco de sementes na superfície do solo foi de $98 \%$ em 2000 (Figura 3 ), dado expressivo para uma técnica simples e de baixa demanda de investimentos. Quando comparadas as profundidades, nota-se que na superfície do solo a redução foi mais elevada que em maiores profundidades, em concordância com dados de Noldin (1995). Provavelmente, esses resultados devem-se à exposição dos grãos às intempéries, proporcionando-lhes condições adequadas à germinação, perda de viabilidade e predação, diminuindo então o potencial de sementes aptas a renovar a população de plantas de arroz-vermelho para a safra seguinte. As sementes de arrozvermelho coletadas nas profundidades de 1-5, 510 e $10-15 \mathrm{~cm}$, com um ano de pousio, apresentaram redução média de 36\%, taxa significativamente inferior à ocorrida na superfície (98\%) no primeiro ano. Observou-se que a taxa de redução nas demais profundidades esteve abaixo das obtidas na superfície; no entanto, com dois anos de pousio atingiu-se redução média de 90, 78 e $85 \%$ nas profundidades de 1-5, 5-10 e 10-15 cm, respectivamente. Esses dados encontram suporte nos relatos de Kellman (1978), o qual afirma que, ao se impedir a entrada de sementes para o banco de sementes no solo, o seu tamanho tende a diminuir, com taxa constante no decorrer do tempo e variações inversas à profundidade.

No que se refere à percentagem de sementes encontradas em cada camada de solo (Figura 4), nota-se que no primeiro ano aquelas encontradas na superfície do solo corresponderam a $81 \%$ do banco de sementes total, indicando que a maior parte daquelas presentes na área estava em local mais favorável à germinação, sendo imprescindível mantê-las neste lugar, sem cultivo de arroz na área, para reduzir o estoque de sementes. Por outro lado, no segundo ano, a quantidade de sementes que estavam na superfície do solo representou apenas $10 \%$ do banco de sementes total e, no terceiro ano, apenas $2 \%$.

Com base nesses resultados e naqueles expostos nas Figuras 2 e 4, em que a grande quantidade de sementes no solo no final do primeiro

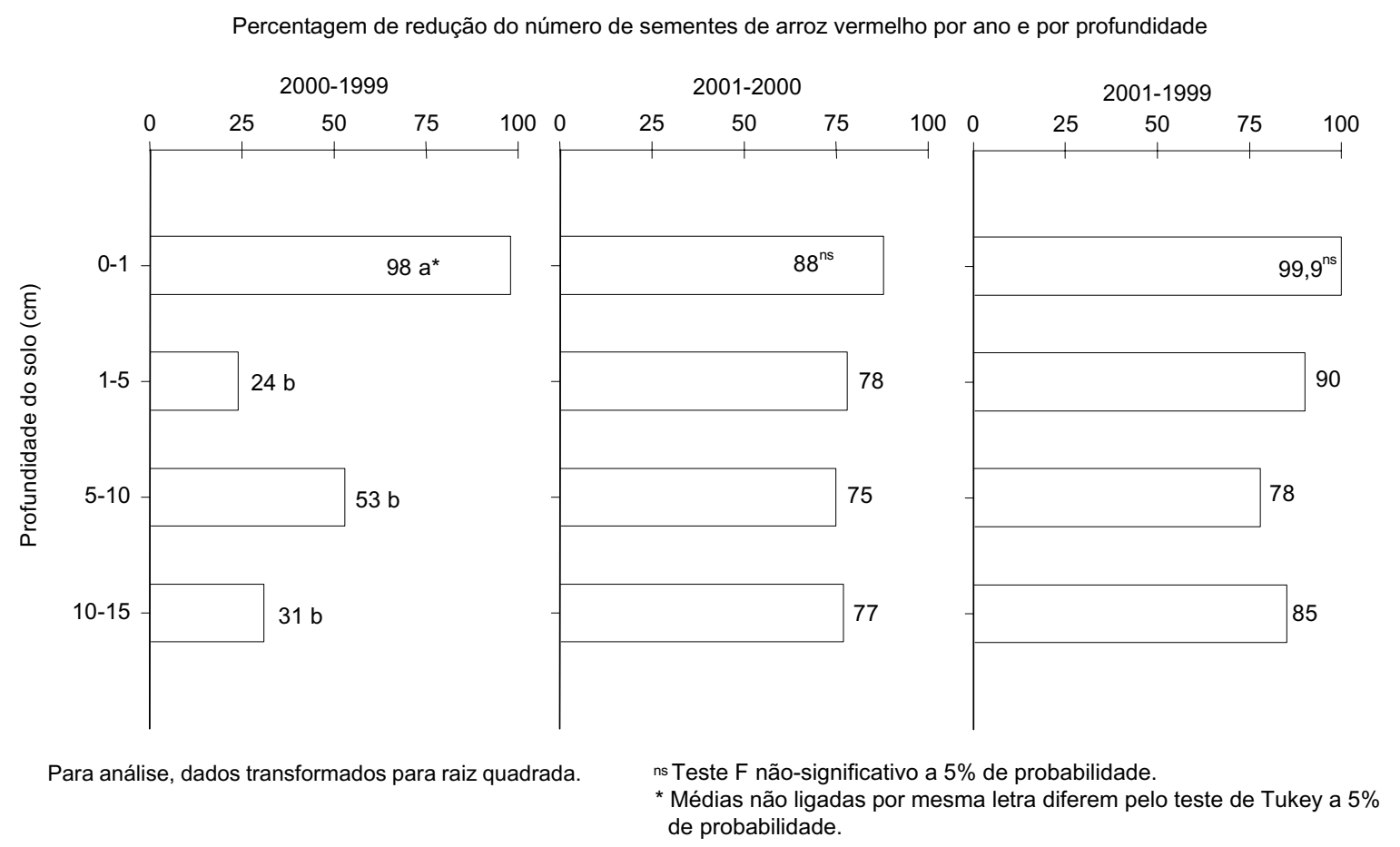

Figura 3 - Média das percentagens de redução do banco de sementes sob diferentes profundidades e entre os anos, em resposta ao pisoteio bovino. Santa Maria-RS. 2001. 


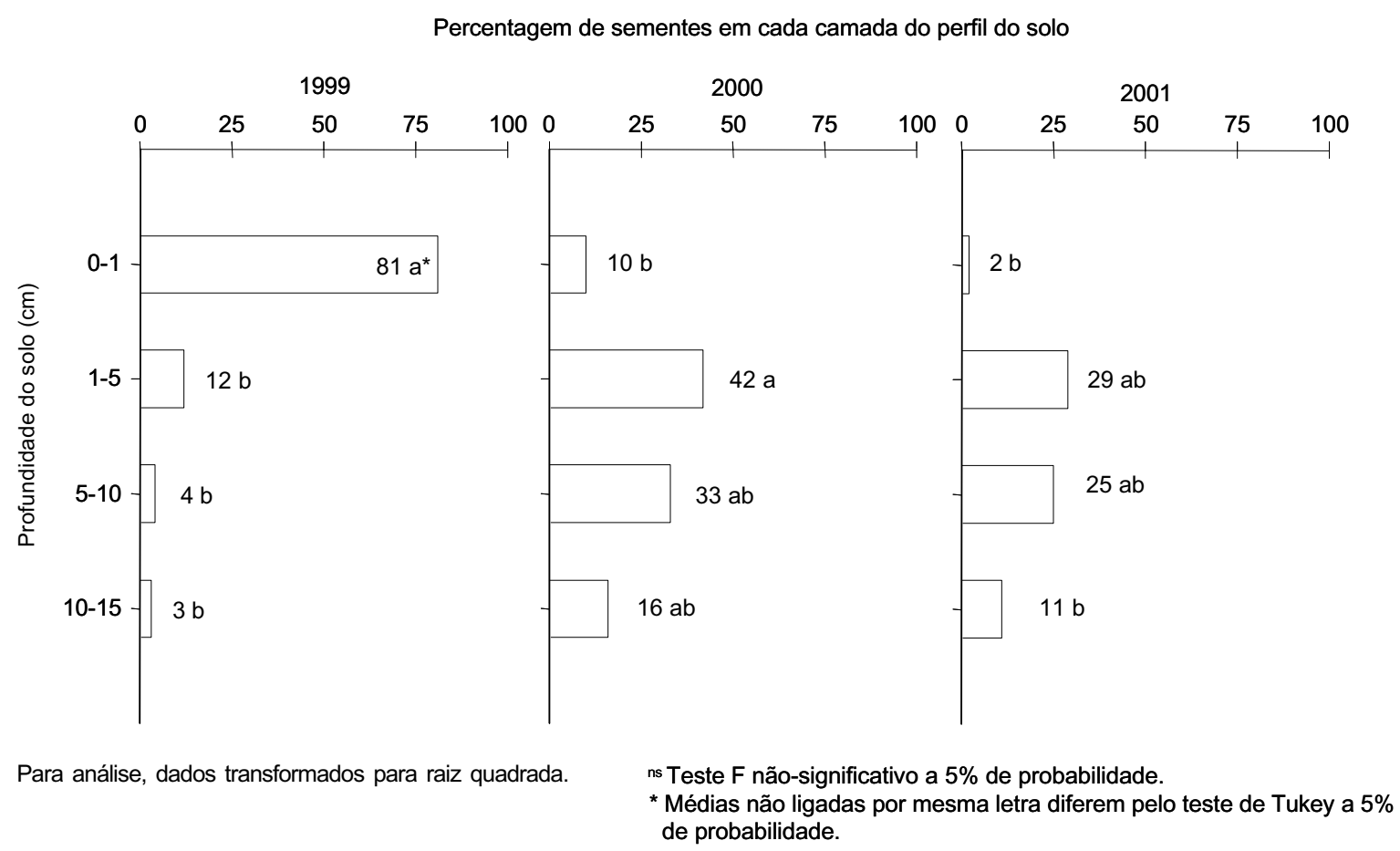

Figura 4 - Distribuição percentual de sementes viáveis no perfil do solo nos três anos de avaliação. Santa Maria-RS. 2001.

ano estava na profundidade de $1-10 \mathrm{~cm} \mathrm{(>75 \%}$ das sementes), vê-se que uma prática de manejo que teoricamente poderia auxiliar na redução mais efetiva do banco de sementes seria a combinação de œousio e mobilização do solo, com o pousio do solo no primeiro ano após a colheita do arroz, seguido, nos meses de dezembro e janeiro, de uma ou mais movimentações do solo até cerca de $10 \mathrm{~cm}$ de profundidade; a partir de então não haverá mobilização do solo até o preparo para a safra seguinte, o que proporcionaria exposição destas sementes à superfície do solo ou redistribuição no perfil, expondo-as às condições necessárias à perda de viabilidade ou predação. Entretanto, isso se constitui numa hipótese de trabalho que precisa ser comprovada experimentalmente.

De acordo com os resultados apresentados, conclui-se que o pousio do solo, com ou sem pisoteio animal, reduz o banco de sementes de arroz-vermelho, com média de $85 \%$ de redução por ano; as sementes situadas na superfície do solo perdem a viabilidade mais rapidamente, comparadas àquelas que se encontram no perfil do solo.

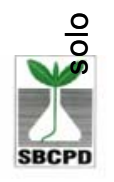

O pisoteio animal não interfere na dinâmica do banco de sementes de arroz-vermelho.

\section{LITERATURA CITADA}

AVILA, L. A. et al. Evolução do banco de sementes e controle do arroz-vermelho em diferentes sistemas de manejo do solo de várzea. Planta Daninha, v. 18, n. 2, p. 217-230, 2000 .

BENECH-ARNOLD, R. L. et al. Environmental control of dormancy in weed seed soil banks in soils. Field Crops Research, v. 67, p. 105-122, 2000.

CARMONA, R. Problemática e manejo de bancos de sementes de invasoras em solos agrícolas. Planta Daninha, v. 40 , n. 12 , p. 5-16, 1992.

\section{EMPRESA BRASILEIRA DE PESQUISA}

AGROPECUÁRIA - EMBRAPA: Invasora do arroz acarreta perda de R\$ 250 milhões todo ano. Disponível em: $<$ http//:www.embrapa.br> Acesso em: 30 de ago., 2001.

FORCELLA, F. et al. Modeling seedling emergence. Field Crops Res., v. 67, p. 123-139, 2000.

GEALY, D. R.; SALDAIN, N. E.; TALBERT, R. E. Emergence of red rice (Oryza sativa) ecotypes under dry-seeded rice (Oryza sativa) culture. Weed Technol., v. 14, n. 2, p. 406-412, 2000.

Planta Daninha, Viçosa-MG, v.21, n.1, p.55-62, 2003 
GHERSA, C. M.; MARTINEZ-GHERSA, M. A.; BENECH-ARNOLD, R. L. Seed dormancy implications for grain and forage. J. Prod. Agric., v. 10, p. 111-117, 1997.

GOSS, W. L.; BROWN, W. Buried red rice seed. J. Am. Soc. Agron., v. 31, n. 7, p. 633-637, 1939.

HELPERT, C. W. Dormancy, germination, and emergence of red rice (Oryza sativa L.). 1981. 92 f. Thesis (Ph.D. Dissertation) - Texas A\&M University, Texas, 1986.

KELLMAN, M. Micro distribution of viable weed seed in two tropical soils. J. Biogeog., v. 5, p. 291-300, 1978.

MARCHEZAN, E. Arroz-vermelho: caracterização, prejuízos e controle. Revisão bibliográfica. Ci. Rural, v. 24, n. 2, p. $415-421,1994$
NOLDIN, J. A. Characterization, seed longevity, and herbicide sensitivity of red rice (Oryza sativa L.) ecotypes, and red rice control in soybeans [Glycine $\max (\mathrm{L}$.

Merr.]. 1995. 218 f. Thesis (Ph.D. Dissertation) - Texas A\&M University, Texas, 1995.

ROCHA, F. F. Manual do teste de tetrazólio em sementes, Brasília: Ministério da Agricultura, AGIPLAN, 1976. 85 p.

VIDOTTO, F.; FERRERO, A. Germination behavior of red rice (Oryza sativa L.) seeds in field and laboratory conditions. Agronomie, v. 20, p. 375-382, 2000. 